\title{
Correction to: Baseline assessment of patient safety culture in primary care centres in Kuwait: a national cross-sectional study
}

Talal ALFadhalah', Buthaina Al Mudaf², Hanaa A. Alghanim³ , Gheed Al Salem4, Dina Ali ${ }^{3}$, Hythem M. Abdelwahab ${ }^{5}$ and Hossam Elamir ${ }^{6 *}$

Correction to: BMC Health Serv Res 21, 1172 (2021)

https://doi.org/10.1186/s12913-021-07199-1

Following publication of the original article [1], it was noted that due to a typesetting error the signs" were removed in Table 2 and its footnote of the pdf version.

The correct table has been included in this correction, and the original article has been corrected.

\footnotetext{
Author details

'Quality and Accreditation Directorate, Ministry of Health, Kuwait City, Kuwait.

${ }^{2}$ Assistant Undersecretary of Public Health Affairs, Ministry of Health, Kuwait

City, Kuwait. ${ }^{3}$ Safety Department, Quality and Accreditation Directorate,

Ministry of Health, Kuwait City, Kuwait. ${ }^{4}$ Accreditation Affairs Department, Quality and Accreditation Directorate, Ministry of Health, Kuwait City, Kuwait.

${ }^{5}$ National Blood Transfusion Services, Ministry of Health and Population, Giza, Egypt. ${ }^{6}$ Research and Technical Support Department, Quality and Accreditation Directorate, Ministry of Health, Kuwait City, Kuwait.
}

Published online: 24 November 2021

\author{
Reference \\ 1. ALFadhalah T, et al. Baseline assessment of patient safety culture in pri- \\ mary care centres in Kuwait: a national cross-sectional study. BMC Health
} Serv Res. 2021;21:1172.

The original article can be found online at https://doi.org/10.1186/s12913021-07199-1.

*Correspondence: dr_hossam_elamir@hotmail.com

${ }^{6}$ Research and Technical Support Department, Quality and Accreditation

Directorate, Ministry of Health, Kuwait City, Kuwait

Full list of author information is available at the end of the article

(C) The Author(s) 2021. Open Access This article is licensed under a Creative Commons Attribution 4.0 International License, which permits use, sharing, adaptation, distribution and reproduction in any medium or format, as long as you give appropriate credit to the original author(s) and the source, provide a link to the Creative Commons licence, and indicate if changes were made. The images or other third party material in this article are included in the article's Creative Commons licence, unless indicated otherwise in a credit line to the material. If material is not included in the article's Creative Commons licence and your intended use is not permitted by statutory regulation or exceeds the permitted use, you will need to obtain permission directly from the copyright holder. To view a copy of this licence, visit http://creativecommons.org/licenses/by/4.0/. The Creative Commons Public Domain Dedication waiver (http://creativeco mmons.org/publicdomain/zero/1.0/) applies to the data made available in this article, unless otherwise stated in a credit line to the data. 
Table 2 Percentage of positive ratings for each survey item, composite and outcome compared to international, regional and national benchmarks

\begin{tabular}{|c|c|c|c|c|c|c|c|}
\hline \multirow{2}{*}{$\begin{array}{l}\text { Survey item } \\
\text { 1. Teamwork }\end{array}$} & \multirow{2}{*}{$\begin{array}{l}\text { Kuwait } 2018 \\
87.8\end{array}$} & \multicolumn{2}{|c|}{ US 2018} & \multicolumn{2}{|c|}{ Yemen 2015} & \multicolumn{2}{|l|}{$\begin{array}{l}\text { Kuwait } \\
2014^{*}\end{array}$} \\
\hline & & 86.5 & -4 & 96.0 & -4 & $80.3^{\mathrm{a}}$ & -4 \\
\hline 1.1. When someone in this centre gets really busy, others help out (22) & 87.1 & 86 & & 97 & & 68.0 & \\
\hline 1.2. In this centre, there is a good working relationship between staff and providers (23) & 88.3 & 90 & & 97 & & & \\
\hline 1.3. In this centre, we treat each other with respect (26) & 92.0 & 85 & & 96 & & 86.0 & \\
\hline 1.4. This centre emphasises teamwork in taking care of patients (34) & 83.8 & 85 & & 94 & & 87.0 & \\
\hline 2. Work Pressure and Pace & 28.4 & 46.3 & $\boldsymbol{\nabla} \boldsymbol{\nabla}$ & 57.3 & $\boldsymbol{\nabla} \boldsymbol{\nabla}$ & $41.0^{\mathrm{b}}$ & $\boldsymbol{\nabla} \nabla$ \\
\hline 2.1. In this centre, we often feel rushed when taking care of patients (24R) & 20.1 & 38 & & 67 & & 24.0 & \\
\hline 2.2. We have too many patients for the number of providers in this centre (27R) & 12.2 & 45 & & 58 & & & \\
\hline 2.3. We have enough staff to handle our patient load (32) & 50.6 & 46 & & 49 & & 58.0 & \\
\hline 2.4. This centre has too many patients to be able to handle everything effectively (35R) & 30.7 & 56 & & 55 & & & \\
\hline 3. Staff Training & 72.4 & 72.3 & -4 & 68.3 & -4 & c & \\
\hline 3.1. This centre trains staff when new processes are put into place (25) & 81.2 & 76 & & 57 & & & \\
\hline 3.2. This centre makes sure staff get the on-the-job training they need (28) & 77.8 & 75 & & 74 & & & \\
\hline 3.3. Staff in this centre are asked to do tasks they haven't been trained to do (31R) & 58.1 & 66 & & 74 & & & \\
\hline 4. Office Processes and Standardisation & 65.5 & 67.5 & -4 & 64.8 & -4 & c & \\
\hline 4.1. This centre is more disorganised than it should be (29R) & 59.5 & 64 & & 46 & & & \\
\hline 4.2. We have good procedures for checking that work in this centre was done correctly (30) & 79.0 & 71 & & 73 & & & \\
\hline 4.3. We have problems with workflow in this centre (33R) & 48.3 & 53 & & 59 & & & \\
\hline 4.4. Staff in this centre follow standardised processes to get tasks done (36) & 75.4 & 82 & & 81 & & & \\
\hline 5. Communication Openness & 54.4 & 69.5 & $\boldsymbol{\nabla}$ & 58.5 & -4 & $51.0^{\mathrm{a}}$ & -4 \\
\hline 5.1. Providers in this centre are open to staff ideas about how to improve centre processes (37) & 59.2 & 73 & & 53 & & 70.0 & \\
\hline 5.2. Staff are encouraged to express alternative viewpoints in this centre (38) & 52.3 & 73 & & 48 & & 37.0 & \\
\hline 5.3. Staff are afraid to ask questions when something does not seem right (40R) & 54.1 & 73 & & 72 & & 46.0 & \\
\hline 5.4. It is difficult to voice disagreement in this centre (46R) & 51.9 & 59 & & 61 & & & \\
\hline 6. Patient Care Tracking/Follow-up & 70.6 & 86.3 & $\boldsymbol{\nabla}$ & 52.3 & $\Delta$ & c & \\
\hline $\begin{array}{l}\text { 6.1. This centre reminds patients when they need to schedule an appointment for preventive or routine } \\
\text { care (39) }\end{array}$ & 72.9 & 88 & & 60 & & & \\
\hline 6.2. This centre documents how well our chronic-care patients follow their treatment plans (41) & 77.1 & 80 & & 55 & & & \\
\hline $\begin{array}{l}\text { 6.3. Our centre follows up when we do not receive a report we are expecting from an outside provider } \\
\text { (42) }\end{array}$ & 51.3 & 86 & & 26 & & & \\
\hline 6.4. This centre follows up with patients who need monitoring (45) & 81.3 & 91 & & 68 & & & \\
\hline 7. Communication about Error & 57.7 & 72.0 & $\boldsymbol{\nabla}$ & 67.0 & $\boldsymbol{\nabla}$ & $51.3^{\mathrm{a}}$ & $\Delta$ \\
\hline 7.1. Staff feel like their mistakes are held against them (43R) & 33.1 & 63 & & 67 & & 33.0 & \\
\hline 7.2. Providers and staff talk openly about centre problems (44) & 57.2 & 64 & & 79 & & 53.0 & \\
\hline 7.3. In this centre, we discuss ways to prevent errors from happening again (47) & 72.1 & 82 & & 74 & & 68.0 & \\
\hline 7.4. Staff are willing to report mistakes they observe in this centre (48) & 68.3 & 79 & & 48 & & & \\
\hline 8. Owner/Managing Partner/Leadership Support for Patient Safety & 53.8 & 66.0 & $\boldsymbol{\nabla}$ & 64.0 & $\boldsymbol{\nabla}$ & $54.3^{\mathrm{a}}$ & -4 \\
\hline 8.1. They aren't investing enough resources to improve the quality of care in this centre (49R) & 38.2 & 47 & & 50 & & 47.0 & \\
\hline 8.2. They overlook patient care mistakes that happen over and over (50R) & 50.3 & 78 & & 69 & & 38.0 & \\
\hline 8.4. They place a high priority on improving patient care processes (51) & 80.7 & 80 & & 78 & & 78.0 & \\
\hline $\begin{array}{l}\text { 8.5. They make decisions too often based on what is best for the centre rather than what is best for } \\
\text { patients ( } 52 \mathrm{R})\end{array}$ & 45.9 & 59 & & 59 & & & \\
\hline 9. Organisational Learning & 78.8 & 78.7 & -4 & 83.3 & -4 & $67.0^{\mathrm{b}}$ & $\boldsymbol{\Delta}$ \\
\hline 9.1. When there is a problem in our centre, we see if we need to change the way we do things (53) & 80.8 & 83 & & 86 & & & \\
\hline $\begin{array}{l}\text { 9.2. This centre is good at changing centre processes to make sure the same problems don't happen } \\
\text { again (57) }\end{array}$ & 78.2 & 79 & & 64 & & 67.0 & \\
\hline $\begin{array}{l}\text { 9.3. After this centre makes changes to improve the patient care process, we check to see if the changes } \\
\text { worked (59) }\end{array}$ & 77.4 & 74 & & 100 & & 67.0 & \\
\hline 10. Overall Perceptions of Patient Safety and Quality & 57.4 & 77.3 & $\boldsymbol{\nabla}$ & 76.8 & $\boldsymbol{\nabla}$ & $30.0^{\mathrm{d}}$ & $\Delta$ \\
\hline 10.1. Our centre processes are good at preventing mistakes that could affect patients (54) & 76.8 & 85 & & 87 & & & \\
\hline 10.2. Mistakes happen more than they should in this centre (55R) & 65.8 & 77 & & 98 & & & \\
\hline 10.3. It is just by chance that we don't make more mistakes that affect our patients (56R) & 43.2 & 77 & & 85 & & & \\
\hline
\end{tabular}


Table 2 (continued)

\begin{tabular}{|c|c|c|c|c|c|c|}
\hline Survey item & Kuwait 2018 & US 20 & & Yeme & n 2015 & $\begin{array}{l}\text { Kuwait } \\
2014^{*}\end{array}$ \\
\hline 10.4. In this centre, getting more work done is more important than quality of care (58R) & 43.8 & 70 & & 37 & & 30.0 \\
\hline Average patient safety culture percentage across all composites & 62.7 & 72.1 & $\boldsymbol{\nabla}$ & 68.4 & -4 & 53.6 \\
\hline List of Patient Safety and Quality Issues & 81.3 & 84.7 & -4 & NR & & NA \\
\hline A patient was unable to get an appointment within $48 \mathrm{~h}$ for an acute/serious problem & 79.6 & 76 & & NR & & NA \\
\hline The wrong chart/medical record was used for a patient & 84.7 & 97 & & NR & & NA \\
\hline A patient's chart/medical record was not available when needed & 80 & 93 & & NR & & NA \\
\hline Medical information was filed, scanned, or entered into the wrong chart/medical record & 86.2 & 95 & & NR & & NA \\
\hline Medical equipment was not working properly or was in need of repair or replacement & 76.1 & 89 & & NR & & NA \\
\hline A pharmacy contacted our centre to clarify or correct a prescription & 76.2 & 61 & & NR & & NA \\
\hline A patient's medication list was not updated during his or her visit & 80.4 & 79 & & NR & & NA \\
\hline The results from a lab or imaging test were not available when needed & 80 & 79 & & NR & & NA \\
\hline A critical abnormal result from a lab or imaging test was not followed up within 1 business day & 88.2 & 93 & & NR & & NA \\
\hline Information Exchange with Other Settings & 81.4 & 79.8 & -4 & NR & & NA \\
\hline Outside labs centres? & 77.9 & 79 & & NR & & NA \\
\hline Outside imaging centres? & 85.3 & 78 & & NR & & NA \\
\hline Pharmacies? & 87.4 & 79 & & NR & & NA \\
\hline Hospitals? & 82.7 & 83 & & NR & & NA \\
\hline Other? & 73.9 & NA & & NR & & NA \\
\hline Overall Ratings on Quality & 54.5 & 68.8 & $\boldsymbol{\nabla}$ & 56.4 & -4 & NA \\
\hline Patient Centred: Is responsive to individual patient preferences, needs, and values & 51.7 & 72 & & 72 & & NA \\
\hline Effective: Is based on scientific knowledge & 54.2 & 72 & & 40 & & NA \\
\hline Timely: Minimises waits and potentially harmful delays & 53.2 & 56 & & 43 & & NA \\
\hline Efficient: Ensures cost-effective care (avoids waste, overuse, and misuse of services) & 52.9 & 61 & & 46 & & NA \\
\hline $\begin{array}{l}\text { Equitable: Provides the same quality of care to all individuals regardless of gender, race, ethnicity, } \\
\text { socio-economic status, language, etc. }\end{array}$ & 60.6 & 83 & & 81 & & NA \\
\hline $\begin{array}{l}\text { Overall Rating on Patient Safety: Overall, how would you rate the systems and clinical processes your } \\
\text { Primary Care Centre has in place to prevent, catch, and correct problems that have the potential to affect } \\
\text { patients? }\end{array}$ & 60.4 & 68 & $\nabla$ & NR & & NA \\
\hline Information Exchange within Your Primary Care Centre & 77.2 & NA & & NA & & NA \\
\hline Primary care centre labs? & 78.3 & NA & & NA & & NA \\
\hline Imaging services within your Primary Care Centre? & 79.2 & NA & & NA & & NA \\
\hline Other clinics/physicians? & 81.8 & NA & & NA & & NA \\
\hline Primary Care Centre pharmacy? & 85.2 & NA & & NA & & NA \\
\hline Other? & 61.3 & NA & & NA & & NA \\
\hline
\end{tabular}

The composite-level percentage of responses is the average of composite items percentages.

The item-level percentage of responses was calculated using the following formula: [number of positive responses to the items in the composite/total number of responses to the items in the composite (excluding missing responses)] $\times 100$.

The number in parentheses after the item is the question number from the survey.

$\mathrm{R}$ : Negatively worded items that were reverse-coded.

$\mathbf{\Delta}$ : Results exceeding the benchmark (greater than $+10 \%$ ).

- : Results meeting the benchmark (between $+10 \%$ and $-10 \%$ ).

$\boldsymbol{\nabla}$ : Results deviating slightly from the benchmark (between $-10 \%$ and $-30 \%$ ).

$\boldsymbol{\nabla}$ : Results deviating greatly from the benchmark (below $-30 \%$ ).

*: Results are selected from comparable items in the HSOPSC conducted at 3 PHCs

a Three comparable items in the composite

${ }^{b}$ Two comparable items in the composite

${ }^{\mathrm{C}}$ No comparable items in the composite

${ }^{d}$ One comparable items in the composite

$N A$ : Not applicable.

$N R$ : Not reported 